\title{
Socio-economic inequalities in children's nutritional status in Democratic Republic of the Congo in 2017-2018: an analysis of data from a nationally representative survey
}

\author{
Xinran Qi ${ }^{1,2}{ }^{(0)}$, Yifan Zhu ${ }^{1,3,4}$, Yu Wang ${ }^{5}$, Qiwei He ${ }^{1,6}$ (1) , Jiayi Hee ${ }^{7}$, Wei Chen ${ }^{4}$, \\ Rie Takesue ${ }^{8}$ and Kun Tang ${ }^{1, *}$ (1) \\ 'Vanke School of Public Health, Tsinghua University, No. 30 Shuangqing Road, Beijing 100084, People's Republic of \\ China: ${ }^{2}$ School of Nursing, Capital Medical University, Beijing, People's Republic of China: ${ }^{3}$ Xiangya School of \\ Medicine, Central South University, Changsha, People's Republic of China: ${ }^{4}$ Bloomberg School of Public Health, \\ Johns Hopkins University, Baltimore, USA: ${ }^{5}$ School of Management, Ocean University of China, Qingda, People's \\ Republic of China: ${ }^{6}$ School of Medicine, Tsinghua University, Beijing, People's Republic of China: ${ }^{7}$ School of Public \\ Health, The University of Queensland, Brisbane, Australia: ${ }^{8}$ Health Section Programme Division, UNICEF \\ Headquarters, New York, USA
}

Submitted 3 January 2021: Final revision received 26 September 2021: Accepted 28 September 2021: First published online 7 0ctober 2021

\begin{abstract}
Objective: The Democratic Republic of the Congo (DRC) has one of the highest levels of child undernutrition globally; however, little information exists on the underlying socio-economic inequalities resulting in undernutrition. This study aims to examine the differences in the nutritional statuses of children across different wealth quintiles and explores the association between malnutrition in children and related factors.

Design: We utilised the 2018 Multiple Indicator Cluster Survey data. We estimated the prevalence of malnutrition across all twenty-six provinces. The study used the WHO 2006 child growth standards to measure stunting, underweight and wasting. We employed a mixed-effect linear model to analyse the association between nutritional status and healthcare accessibility, domestic sanitation, and socio-demographic factors.

Setting: Twenty-six provinces in the DRC.

Participants: 21477 children under 5 years of age and 21828 women of childbearing age in the DRC.

Results: The national prevalence of underweight, stunting and wasting was found to be $23.33 \%, 42.05 \%$ and $5.66 \%$, respectively. Household wealth and mother's education level were significantly positively associated with the nutritional statuses of children. Among households in the lowest wealth quintile, residence in urban areas was a protective factor against undernutrition.

Conclusion: The findings of this study indicate considerable socio-economic inequalities in the nutritional statuses of children under 5 years of age in the DRC, highlighting the need for nutrition promotion as part of maternal and child healthcare. Interventions and policies should include improving nutrition education for less-educated mothers, in particular, in the central provinces of the DRC.
\end{abstract}

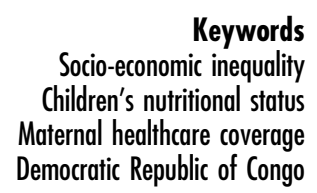

Socio-economic inequality Children's nutritional status Democratic Republic of Congo
The Democratic Republic of the Congo (DRC) is the largest country in sub-Saharan Africa with a population of over 84 million people (2018) ${ }^{(1)}$. The macroeconomic and financial development of the DRC has been rapidly increasing since 2001. The gross domestic product (GDP) of the DRC

Xinran Qi and Yifan Zhu are first authors. increased from $7 \cdot 4$ billion dollars to $50 \cdot 4$ billion dollars in $2019^{(2)}$, making the DRC one of the fastest-growing economies in the world ${ }^{(3)}$. Despite the significant economic growth and abundance of mineral and agricultural resources, large disparities between socio-economic statuses continue to exist in the DRC. According to data from the World Bank, $73 \%$ of the Congolese population, or approximately 
60 million people in 2018 , lived on less than $\$ 1.90$ a day, and one out of six people lived in extreme poverty ${ }^{(4)}$. Over the past decade, the DRC has been affected by waves of civil wars and unceasing domestic conflicts. Violence, mass displacement and the destruction of infrastructure have devastated the health of the population ${ }^{(5,6)}$. As of 2008, an estimated 5.4 million deaths occurred as a result of the armed conflict between 1998 and $2007^{(7)}$, mainly due to disease and starvation ${ }^{(8)}$.

The DRC has among the highest percentages of chronic child malnutrition, or stunting, in the world with lasting consequences for the children who suffer from this nutritional disorder ${ }^{(9)}$. Malnutrition during early childhood is associated with adverse effects on cognitive and physical development ${ }^{(10,11)}$ and failure of proper development during the 'critical age window of 1000 days' can lead to cognitive and physical deficits in adulthood ${ }^{(12,13)}$. This can in turn result in poorer educational and economic outcomes $^{(14-16)}$. According to the 2018 Human Capital Index (HCI) which measures the survival of children using key health determinants, the DRC ranked 146 out of 157 countries ${ }^{(17)}$, indicating high mortality rates in children in the DRC.

Apart from the effects of malnutrition on stunting, studies have examined the association between factors such as socio-economic inequalities due to unequal distribution of power, wealth and resources with stunting in children ${ }^{(18-21)}$. Higher educational attainments of parents and place of residence were found to be positively related to the nutritional statuses of children ${ }^{(19,22-24)}$. However, there is a need for studies to further explore the risk of stunting at different levels of determination to identify key factors contributing to the progression of stunting in the DRC, especially at a national level. For this study, a conceptual framework for determinants of malnutrition was utilised to compare the importance of determinants (e.g. geographical and socio-economic indicators) at different levels and their impacts on household income and health service inequalities in the $\mathrm{DRC}^{(25)}$. The findings of this study aim to provide decision-makers with comparative information on the impact of different factors affecting the nutritional statuses of children to provide empirical and evidence-based guidance to inform future interventions and policies ${ }^{(20,26-29)}$.

\section{Methods}

\section{Data}

Data from the 2018 Multiple Indicator Cluster Survey (MICS-Palu) were utilised for this study. The MICS is a nationally representative household survey of children aged $0-5$ years, women aged $15-49$ years and men aged 15-59 years. This survey was conducted by the National Institute of Statistics and the Ministry of Planning of the DRC, in collaboration with the UNICEF and the United
States Agency for International Development/Centres for Disease Control (USAID/CDC). The MICS generated more than 150 key indicators that provided disaggregated data on the situation of children and women, and the living situations of the population in the areas of health, nutrition, education, security, hygiene and sanitation.

Multi-stage stratified cluster sampling was employed for the selection of the survey sample. Both urban and rural areas across all twenty-six provinces in the DRC were included. Additionally, urban and rural areas were identified as the main sampling strata using a two-stage selection method. The urban and rural areas within each province were identified as the main sampling strata, and the sample of households was selected in two stages. Within each stratum, 721 clusters were selected systematically with probability proportional to size. After a household listing was carried out within the cluster, a systematic sample of thirty households was drawn in each cluster.

\section{Variables}

Height-for-age $Z$ score (HAZ), weight-for-age $Z$ score (WAZ) and weight-for-height $Z$ score (WHZ) were analysed using the 2006 WHO child growth standards ${ }^{(30)}$. A plausibility criterion of -6 to $6 \mathrm{SD}$ from the median of the reference population has been used for WAZ and WHZ, and -7 to $7 \mathrm{SD}$ from the median of the reference population for HAZ. We defined stunting as HAZ more than 2 SD below the median of the reference population, underweight as WAZ more than 2 SD below the median, wasting as WHZ more than $2 \mathrm{sD}$ below the median and overweight as WHZ more than 2 SD above the median.

Four outcomes of maternal healthcare were selected for our study: delivery at a healthcare facility (public/private), antenatal care coverage (defined as four or more antenatal care visits), skilled attendants at birth and postnatal care (defined as a health check-up while in the facility or at home following delivery, or a postnatal care visit within $2 \mathrm{~d}$ after delivery).

Handwashing behaviours, clean water sources and improved toilet facilities were selected to analyse household sanitation. Correct handwashing behaviour was assessed using the availability of proper handwashing facilities, clean water and soap. Improved sources of drinking water were assessed with the use of the following types of water supply: piped water, tube well/borehole, protected dug well, protected spring, rainwater collection, and packaged or delivered water. Improved toilet facilities were assessed with the use of flush or pour flush to piped sewer systems, septic tanks, or pit latrines, ventilated improved pit latrines, pit latrines with slabs, and composting toilets.

Household economic status (measured using the wealth index) was utilised to measure health inequalities. Principal components analysis was performed to construct the 
wealth index by using the information on the ownership of consumer goods, dwelling characteristics and other characteristics that were related to household's wealth, to generate weights (factor scores) for each of the items used ${ }^{(31)}$. Highest educational attainment of mothers (no formal education or pre-school, primary school, secondary school, and tertiary and above), child's weight at birth, age (in months), sex (male or female) and place of residence (rural or urban) were also taken into account.

\section{Statistical analysis}

Univariable and multivariable associations between the nutritional statuses of children and individual determinants such as the child's age and sex, mother's education level, maternal healthcare including the use of qualified birthing facilities, antenatal visits of more than four times, skilled attendants at birth, postnatal care checks, and household determinants including household wealth index and place of residence (urban $v$. rural) were analysed. The covariates were chosen based on previous literature on malnutrition in developing countries ${ }^{(32,33)}$. The mixed-effects model with a random intercept specified at the primary sampling unit level was used to adjust for unmeasured factors that might affect the nutritional status of children. These features of the regression model also account for complex survey design. All the children included in the model were matched to their mother by 'Cluster number, Household number and Mother's line number' provided by the original questionnaires for both adults and children.

\section{Results}

\section{Descriptive characteristics}

The characteristics of the participants are presented in Table 1. A total of 21456 children under 5 years of age and 21756 women of childbearing age in the DRC were analysed for this study. Among the 21456 children under 5 years of age, the participants had a mean age of 2.44 years, a mean HAZ, WAZ and WHZ of $-1 \cdot 6,-1 \cdot 05$ and $0 \cdot 15$, respectively. The national prevalence rate of underweight, stunting and wasting was found to be $23.33 \%$, $42.05 \%$, and $6.54 \%$, respectively, whilst the prevalence rate of overweight was $3.80 \%$. The majority of children resided in rural areas (58.42\%). The majority of mothers had either no formal/pre-school education or primary school education $(53.06 \%)$. For the maternal healthcare coverage, the utility rate of antenatal visits over four times, delivery at health facilities, skilled attendants at birth and postnatal health checks were $43.21 \%, 81.53 \%, 85.20 \%$, and $56.59 \%$, respectively. In terms of domestic sanitation, the coverage of handwashing facilities, improved toilet and improved water were $56.73 \%, 28.77 \%$ and $54.66 \%$, respectively.
Table 1 Descriptive statistics for main variables in the analysis

\begin{tabular}{|c|c|c|c|}
\hline & Mean & Proportion (\%) & SD/SE \\
\hline Child's age (months) & $29 \cdot 35$ & & 0.15 \\
\hline Woman's age (years) & $29 \cdot 08$ & & 0.12 \\
\hline Height-for-age $Z$ score & -1.60 & & 0.04 \\
\hline Weight-for-age $Z$ score & -1.05 & & 0.02 \\
\hline Weight-for-height $Z$ score & $-0 \cdot 15$ & & 0.02 \\
\hline Weight at birth $(\mathrm{kg})$ & $3 \cdot 33$ & & 0.01 \\
\hline Household size & $6 \cdot 74$ & & 0.05 \\
\hline \multicolumn{4}{|l|}{ Child's sex } \\
\hline Male & & $49 \cdot 34$ & 0.50 \\
\hline Female & & $50 \cdot 66$ & 0.50 \\
\hline Stunting & & $42 \cdot 05$ & 1.01 \\
\hline Underweight & & 23.33 & 0.73 \\
\hline Wasting & & 6.54 & 0.41 \\
\hline Overweight & & $3 \cdot 80$ & 0.26 \\
\hline \multicolumn{4}{|l|}{ Mother's education level } \\
\hline Illiteracy & & $18 \cdot 91$ & 1.06 \\
\hline Primary school & & $34 \cdot 15$ & 1.06 \\
\hline Secondary school 1 & & $14 \cdot 28$ & 0.72 \\
\hline Secondary school 2 & & 29.35 & $1 \cdot 10$ \\
\hline Above & & 3.30 & 0.43 \\
\hline \multicolumn{4}{|l|}{ Location of residence } \\
\hline Urban & & 41.58 & 2.57 \\
\hline Rural & & 58.42 & 2.57 \\
\hline \multicolumn{4}{|l|}{ Coverage of maternal healthcare } \\
\hline Antenatal visit over four times & & $43 \cdot 21$ & 1.33 \\
\hline Delivery at health facility & & 81.53 & $1 \cdot 20$ \\
\hline Skilled attendants at birth & & $85 \cdot 20$ & $1 \cdot 16$ \\
\hline Postnatal health checks & & 56.59 & 1.41 \\
\hline \multicolumn{4}{|l|}{ Domestic sanitation } \\
\hline Handwashing & & $56 \cdot 73$ & $2 \cdot 12$ \\
\hline Improved toilet & & $28 \cdot 77$ & 1.84 \\
\hline Improved water & & $54 \cdot 66$ & 2.57 \\
\hline
\end{tabular}

\section{Factors associated with children's nutritional status - socio-economic inequalities}

Figure 1 illustrated the distribution of wealth across all twenty-six provinces in the DRC. Households in the lowest wealth quintile are concentrated among the central provinces of the DRC and account for $46 \%-60 \%$ of households whereas, in western and southeastern provinces such as Kongo Central and Haut-Katanga, households in the lowest wealth quintile accounted for a smaller proportion (9\%-15\% of households). In Kinshasa, however, the proportion of households in the lowest wealth quintile was below $9 \%$.

Nutrition status among children and maternal healthcare access differed across wealth quintiles. Higher household economic status was protective against children's stunting (HAZ) and underweight (WAZ). However, such a protective effect was not found among wasting and overweight (WHZ) in Fig. 2. Therefore, children's nutritional status was mainly assessed by WAZ and HAZ later in this study. Maternal healthcare, including the percentage of mothers with access to qualified birthing locations, antenatal care, skilled attendants at birth and postnatal care, was positively associated with the increasing household wealth (from the lowest to the highest wealth quintile) (Fig. 2). 


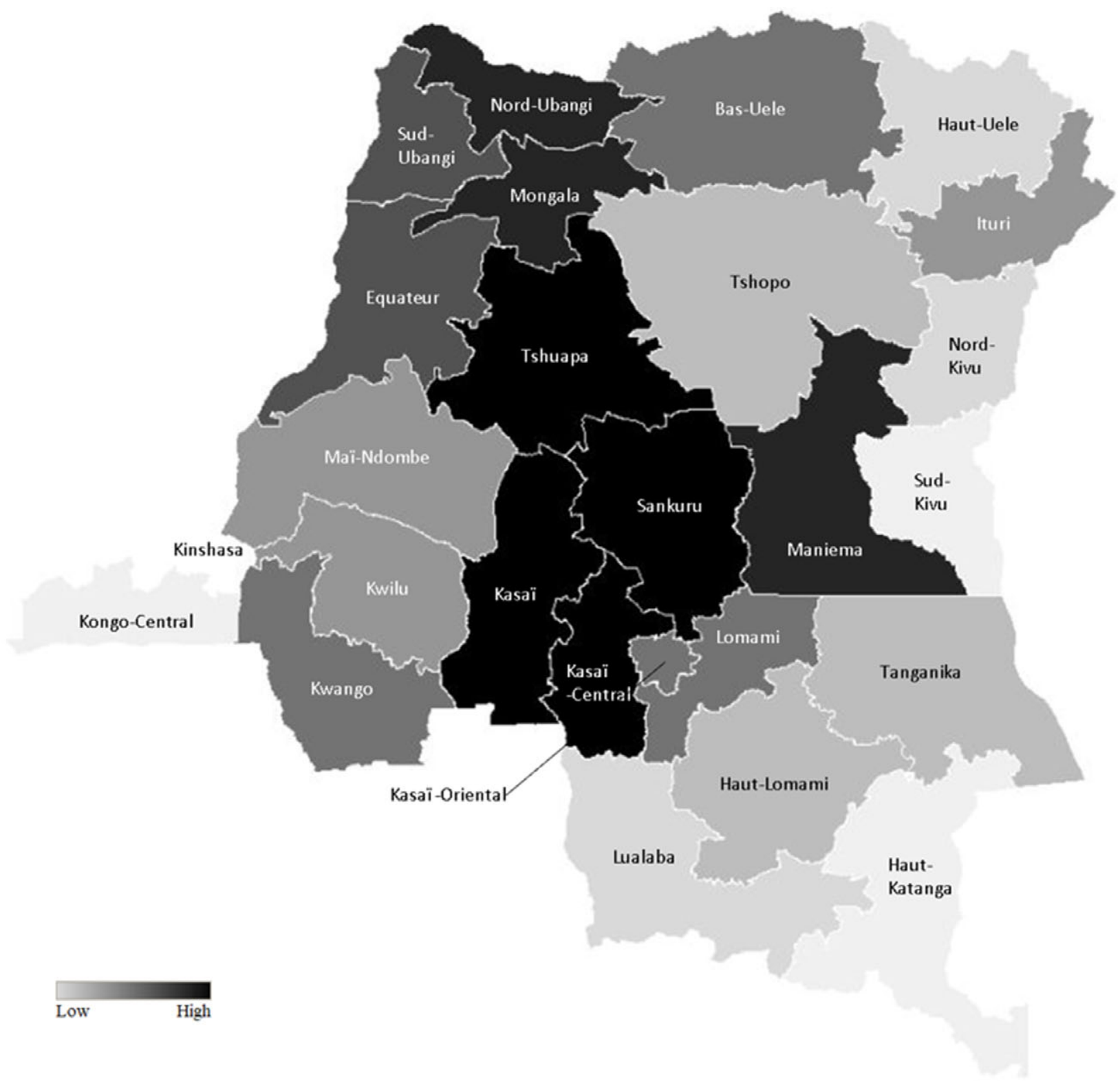

Fig. 1 Distribution of the lowest wealth quintile households across the DRC. DRC, The Democratic Republic of the Congo

After matching, there were 20202 mother-child dyads. Among them, 10959 mothers had given birth within 2 years before the investigation and thus had information on maternal healthcare and were included in the regression analysis. Results from the crude random intercept linear regression estimating the association of the nutritional status of children with mother's maternal healthcare and household socio-demographic factors indicate that among children, HAZ and WAZ were positively associated with maternal healthcare and domestic sanitation (Table 2). However, when employing a multivariable-adjusted regression, there was no statistically significant association between the nutritional status of children and maternal healthcare or domestic sanitation. The wealth index appeared to be positively associated with HAZ and
WAZ. Likewise, mothers' education level was also positively associated with HAZ and WAZ among children. Average WAZ was higher among children whose mothers had secondary level schooling, secondary school and above compared to those whose mothers had no formal schooling.

\section{Factors associated with children's nutritional status and maternal bealthcare access geographical inequalities}

Figure 3 demonstrated province-specific net spatial effects of nutrition status among children, including the prevalence of underweight, stunting, wasting and overweight in the DRC. Darker colours correspond to higher 
(A)
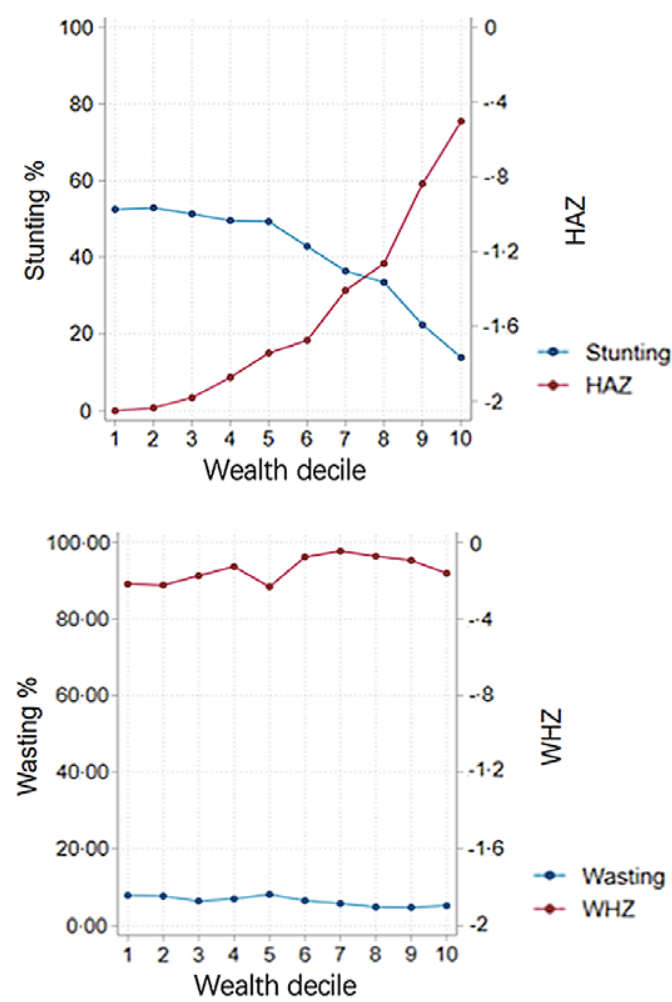

Children's Nutritional Status by Wealth
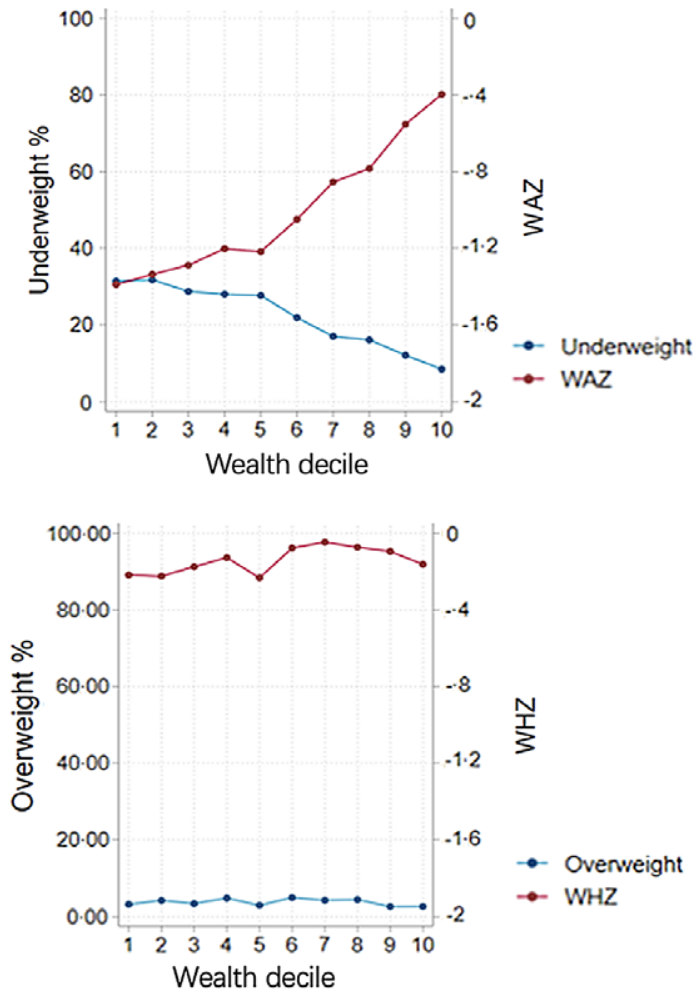
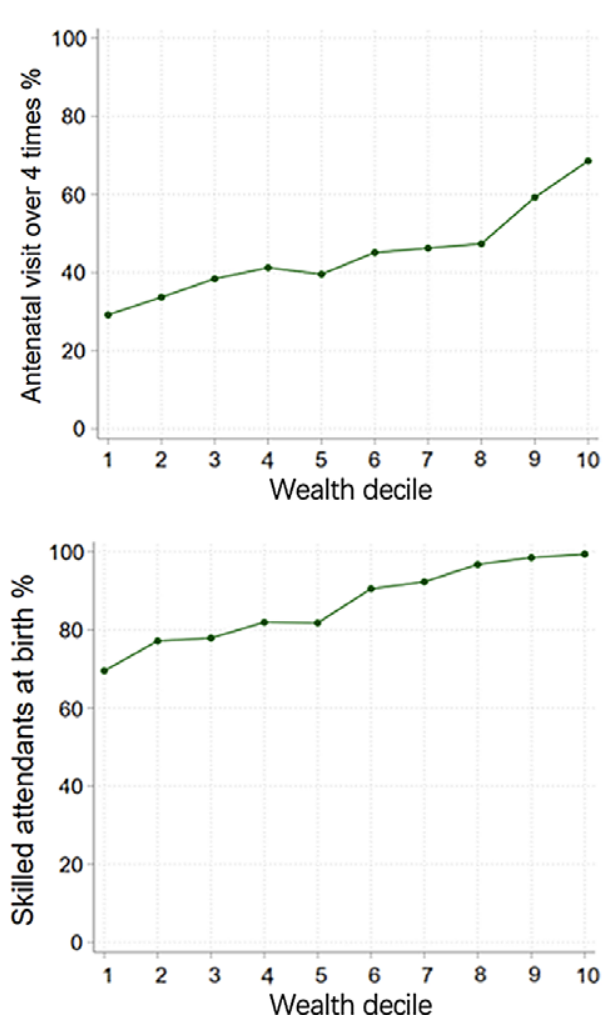

(B)

Maternal Healthcare Access by Wealth
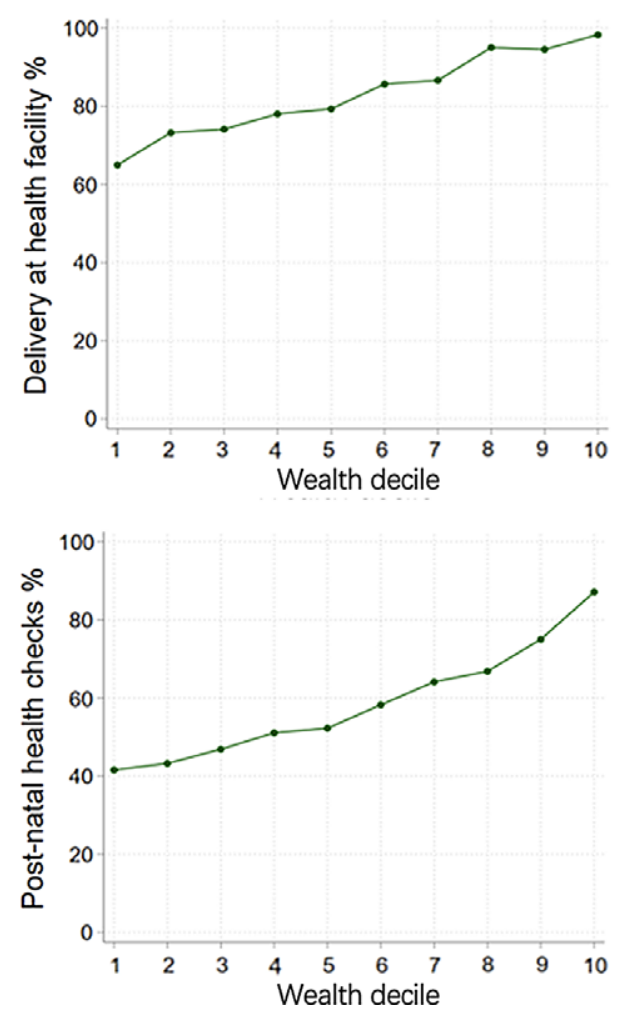

Fig. 2 The children's nutritional status and maternal healthcare indicators according to decile of wealth index 


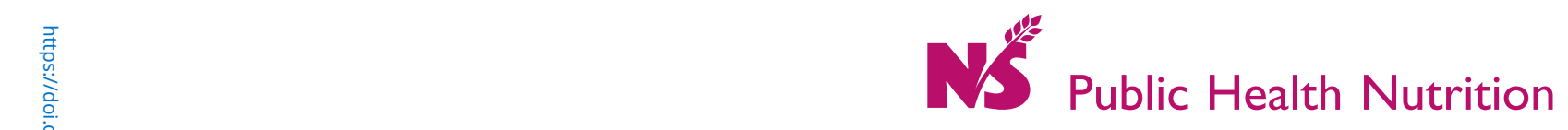

Table 2 Crude and adjusted associations of the nutritional status of children with maternal healthcare for the mother and household socio-demographic factors

\begin{tabular}{|c|c|c|c|c|c|c|c|c|c|c|c|c|c|c|c|c|c|c|}
\hline & \multicolumn{6}{|c|}{ HAZ } & \multicolumn{6}{|c|}{ WAZ } & \multicolumn{6}{|c|}{ WHZ } \\
\hline & \multicolumn{3}{|c|}{ Crude } & \multicolumn{3}{|c|}{ Multivariable-adjusted } & \multicolumn{3}{|c|}{ Crude } & \multicolumn{3}{|c|}{ Multivariable-adjusted } & \multicolumn{3}{|c|}{ Crude } & \multicolumn{3}{|c|}{ Multivariable-adjusted } \\
\hline & Coefficient & $95 \% \mathrm{Cl}$ & $\begin{array}{c}P \\
\text { value }\end{array}$ & Coefficient & $95 \% \mathrm{Cl}$ & $\begin{array}{c}P \\
\text { value }\end{array}$ & Coefficient & $95 \% \mathrm{Cl}$ & $\begin{array}{c}P \\
\text { value }\end{array}$ & Coefficient & $95 \% \mathrm{Cl}$ & $\begin{array}{c}P \\
\text { value }\end{array}$ & Coefficient & $95 \% \mathrm{Cl}$ & $\begin{array}{c}P \\
\text { value }\end{array}$ & Coefficient & $95 \% \mathrm{Cl}$ & $\begin{array}{c}P \\
\text { value }\end{array}$ \\
\hline $\begin{array}{l}\text { Maternal healthcare } \\
\text { index }\end{array}$ & 0.029 & $-0.007,0.065$ & 0.113 & 0.010 & $-0.025,0.046$ & 0.567 & 0.036 & $0.009,0.063$ & 0.009 & 0.024 & $-0.003,0.050$ & 0.084 & 0.024 & $-0.003,0.052$ & 0.085 & 0.022 & $-0.006,0.050$ & 0.117 \\
\hline $\begin{array}{l}\text { Domestic sanitation } \\
\text { index }\end{array}$ & 0.051 & $0.005,0.097$ & 0.029 & -0.031 & $-0.078,0.015$ & 0.189 & 0.030 & $-0.004,0.064$ & 0.081 & -0.018 & $-0.053,0.017$ & 0.318 & 0.003 & $-0.032,0.038$ & 0.884 & 0.001 & $-0.036,0.038$ & 0.963 \\
\hline Wealth index & & & & 0.257 & $0.198,0.315$ & $<0.001$ & & & & 0.145 & $0.101,0.189$ & $<0.001$ & & & & -0.009 & $-0.055,0.037$ & 0.713 \\
\hline \multicolumn{19}{|c|}{ Mother's education (reference: illiteracy) } \\
\hline Primary school & & & & 0.097 & $0.006,0.187$ & 0.037 & & & & 0.101 & $0.034,0.169$ & 0.003 & & & & 0.065 & $-0.005,0.134$ & 0.070 \\
\hline Secondary school 1 & & & & 0.237 & $0.122,0.352$ & $<0.001$ & & & & 0.220 & $0.134,0.306$ & $<0.001$ & & & & 0.123 & $0.034,0.211$ & 0.007 \\
\hline Secondary school 2 & & & & 0.223 & $0.112,0.333$ & $<0.001$ & & & & 0.213 & $0.130,0.295$ & $<0.001$ & & & & 0.108 & $0.023,0.193$ & 0.013 \\
\hline $\begin{array}{l}\text { Above secondary } \\
\text { school }\end{array}$ & & & & 0.410 & $0.147,0.674$ & 0.002 & & & & 0.334 & $0.137,0.531$ & 0.001 & & & & 0.151 & $-0.052,0.354$ & 0.144 \\
\hline
\end{tabular}

HAZ, height-for-age $Z$ score; WAZ, weight-for-age $Z$ score; WHZ, weight-for-height $Z$ score.

Estimations from all models are adjusted for the place of residence (rural/urban), household size, child's age (months) and sex, and mother's age (years). 
Inequalities in children's nutritional status

Stunting

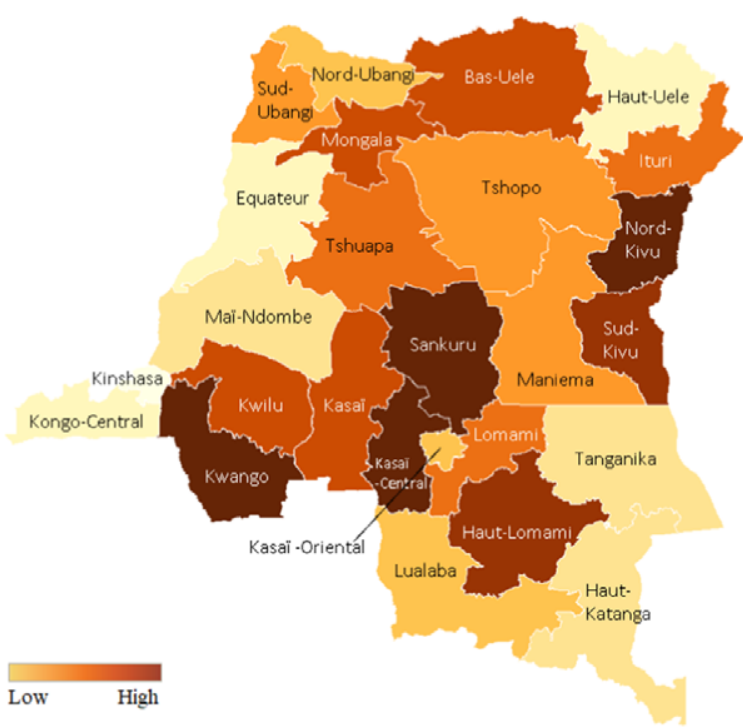

Wasting
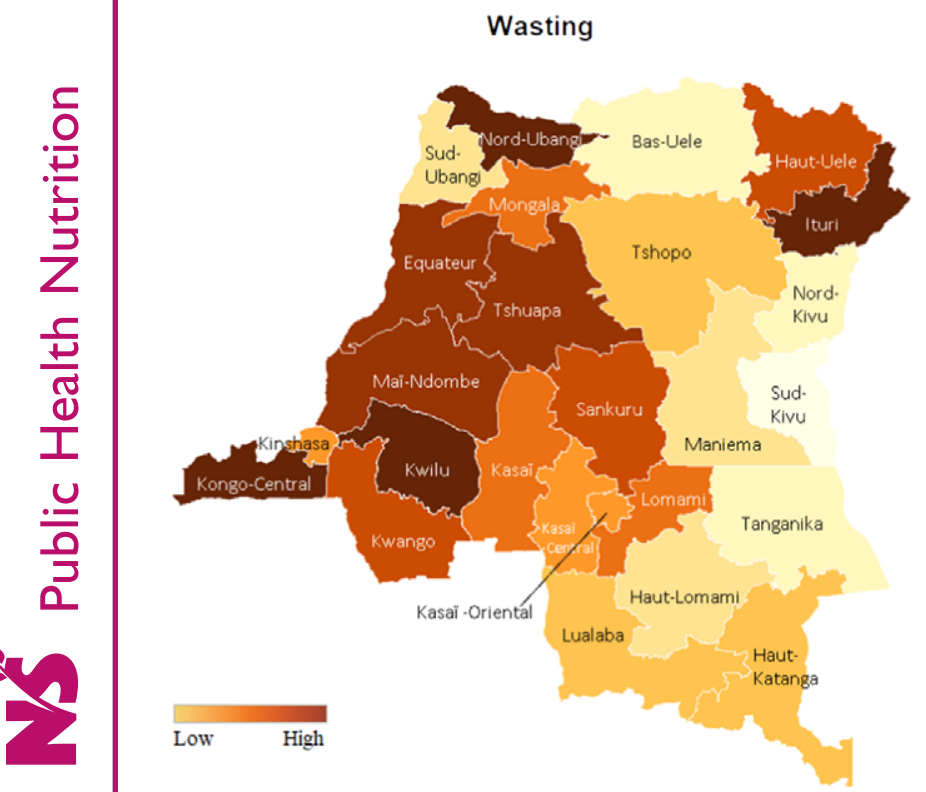

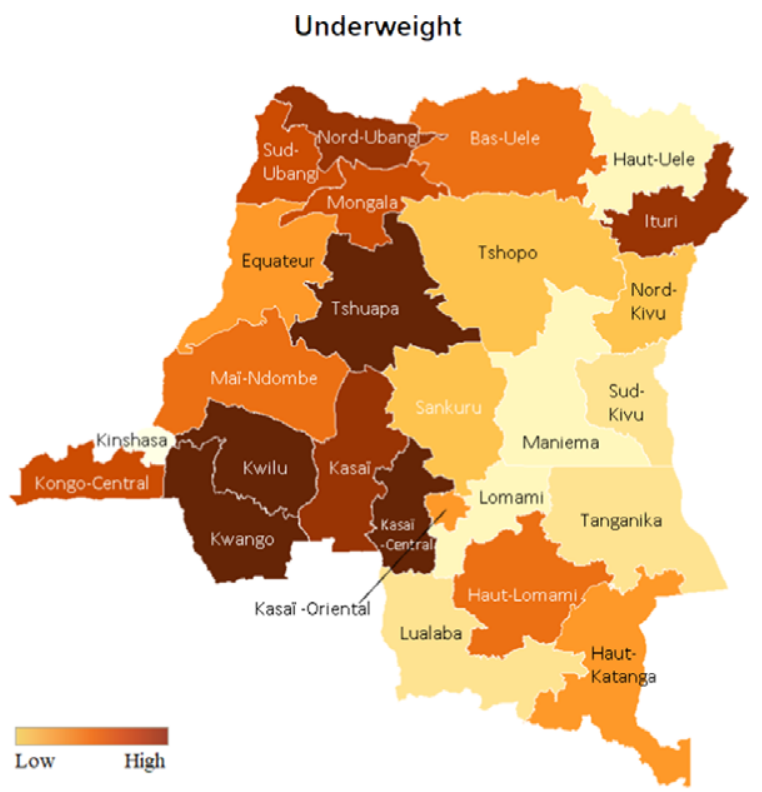

Overweight

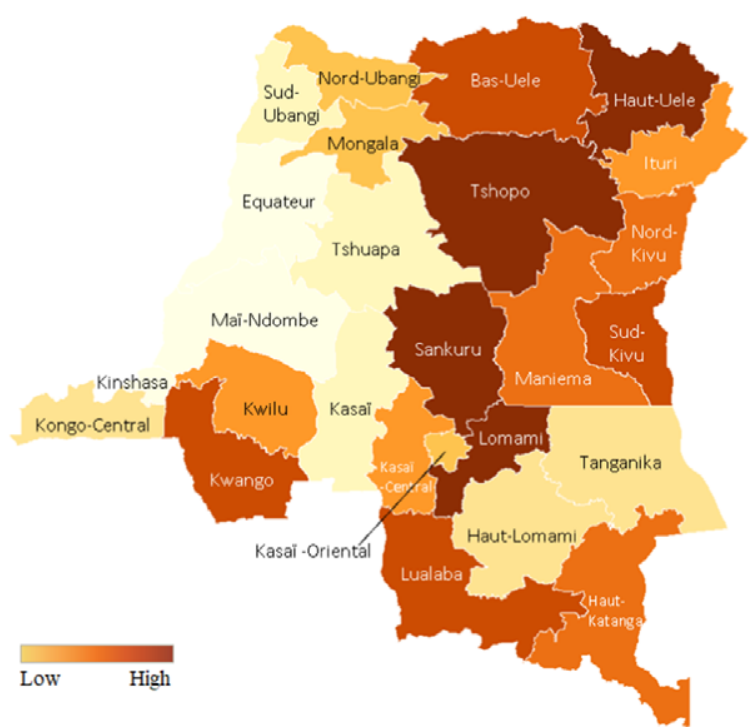

Fig. 3 (colour online) The prevalence of underweight, stunting, wasting and distribution of economic status across the country

prevalence, whereas lighter colours correspond to lower prevalence. Our mapping exhibited three key observations. Firstly, the prevalence of malnutrition among children was generally higher among central provinces in the DRC. Secondly, southwest provinces, including Kwango, Kwilu, Kasaï and Kasaï-Central, exhibited a higher prevalence of stunting and underweight among children. Thirdly, taking into account that eastern provinces are subjected to ongoing conflict, nutrition status was poorer among children in these regions.

Maternal healthcare access coverage, including delivery at health facilities, antenatal care, skilled attendants at birth and postnatal care among women, is demonstrated in Fig. 4. Notably, western, eastern and southeastern provinces, such as Kongo Central,
Kinshasa, and the Haut-Katanga, generally had good maternal healthcare conditions, in contrast to the lowest wealth quintile households being concentrated among the central provinces (Fig. 1). Additionally, it is worth noting that Kinshasa, the capital of the DRC, had both the best maternal healthcare and nutritional status among children in the country.

\section{Factors associated with children's nutritional status (children's height-for-age $Z$ score and weight-for-age $Z$ score) stratified by the lowest/ bighest wealth quintile in rural and urban settings}

In the multivariable-adjusted analysis in Table 3, we stratified individuals from the lowest and highest wealth quintile 


\section{Skilled Attendant at Birth}

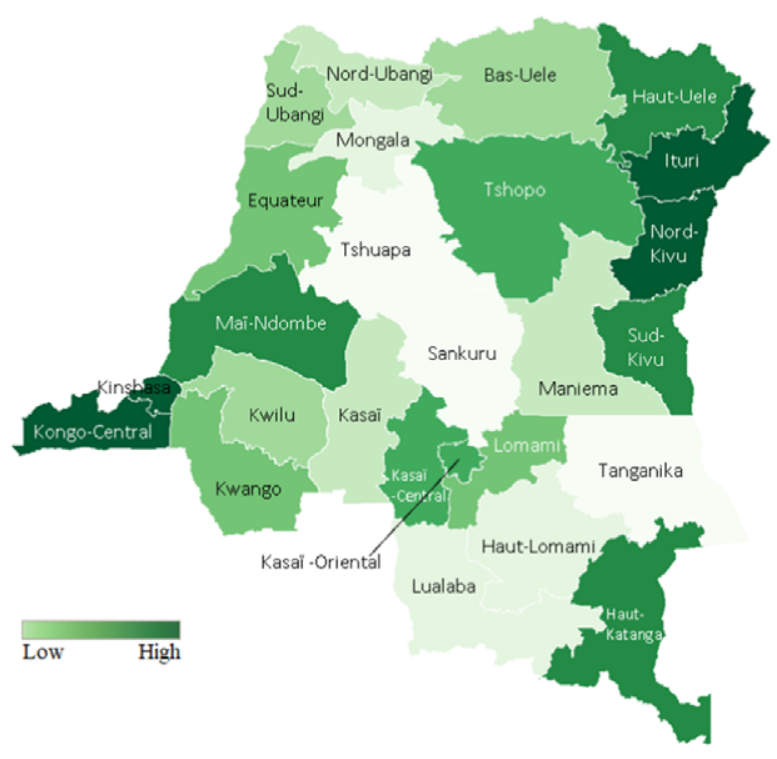

Postnatal Health Checks

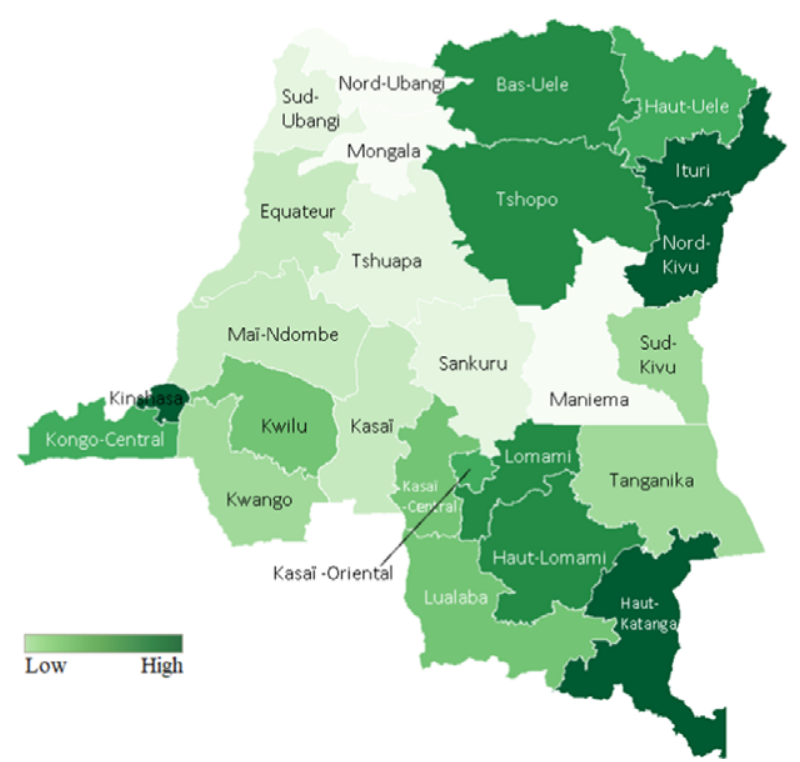

Atenatal Examination

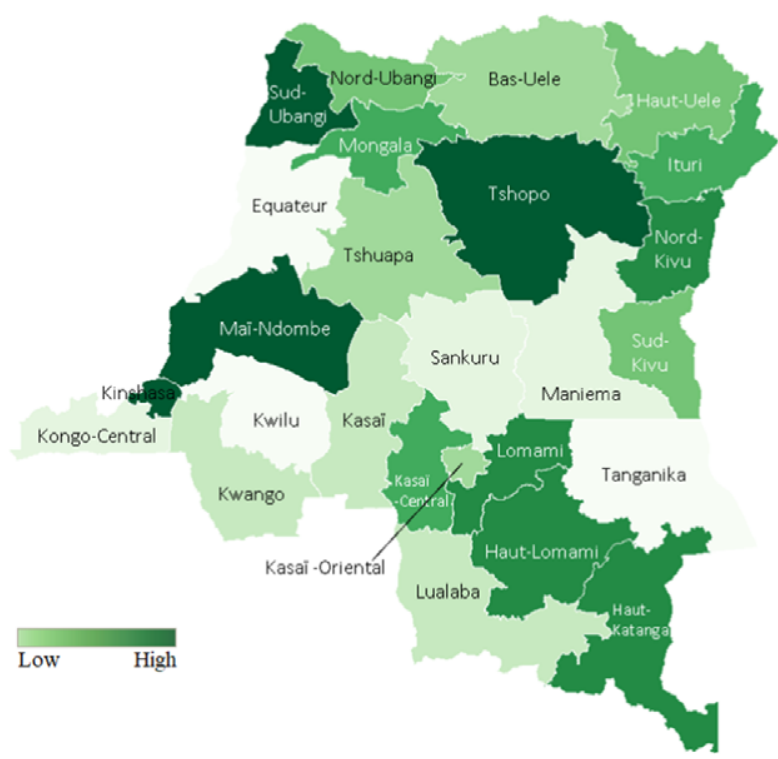

Qualified Birth Location

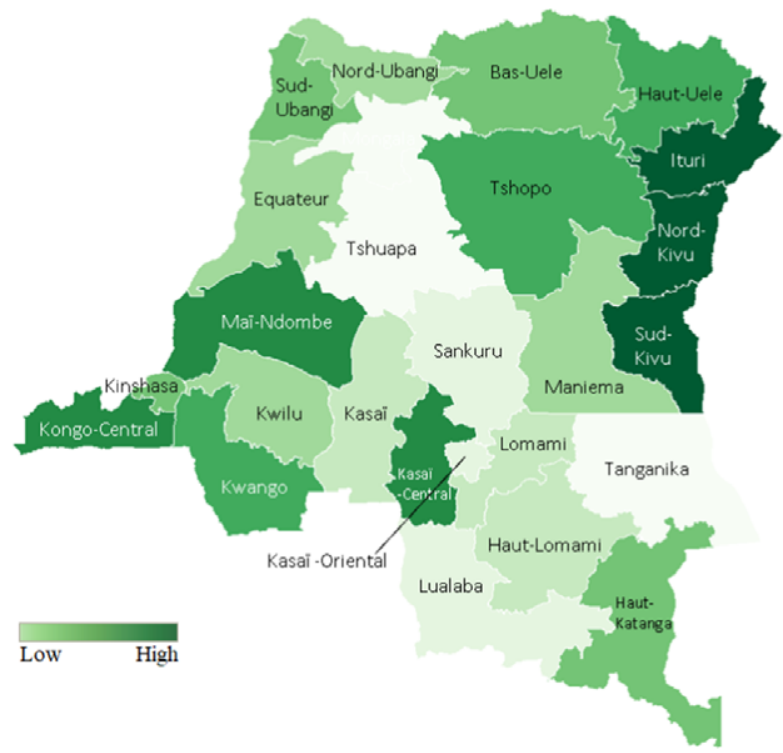

Fig. 4 (colour online) The coverage of qualified birth delivery location, antenatal care (ANC), skilled attendants at birth and postnatal care (PNC) among women

and find that neither maternal healthcare index nor domestic sanitation index was associated with children's HAZ and WAZ. Individuals falling within the lowest wealth quintile and living in rural areas had a lower HAZ (-0.585 (95\% CI $0.871,-0.300) ; P<0.001)$ compared to those living in urban areas. Additionally, the mother's education level was found to be a protective factor of children's nutritional status. Average WAZ was higher among children whose mother had secondary school 2 (0.385 (95\% CI 0.161, 0.609); $P=0.001)$ and above secondary school (0.652 (95\% CI $0.222,1.082) ; P=0.003)$ education levels compared to children whose mothers had no schooling. Among the children falling within the highest wealth quintile, WAZ has a significant association with the wealth index only. On average, a one-score increase in wealth index was associated with a 0.347 increase in WAZ ((95\% CI 0.119, 0.576); $P=0.003)$. Furthermore, among those in the highest wealth quintile, there was no statistically significant association between the area of residence, mother's education level and children's nutritional status. Additionally, the result for the WHZ of children was also presented in the Appendix. 


\section{Discussion}

This study illustrates the DRC's national profile of malnutrition among children between 2017 and 2018 using the nationally representative MICS survey. In comparison to the DRC's MICS survey between 2010 and 2017(34), the prevalence of stunting decreased from $43 \%$ to $42 \%$, the prevalence of underweight decreased from $29 \%$ to $23 \%$ and the prevalence of wasting decreased from $7 \%$ to $6.5 \%$, respectively. This trend is comparable to findings from the DRC's 2013 Demographic Health Survey (DHS) ${ }^{(34)}$, where the prevalence of stunting, underweight and wasting were $43 \%, 22.6 \%$ and $7.9 \%$, respectively. In addition, a recent study that assessed malnutrition among children in forty-seven low-income and middle-income countries using 4-6 rounds of MICS $^{(35)}$ between 2010 and 2017 found that the overall average rate of stunting, underweight and wasting was $32.5 \%, 18.7 \%$, and $4.6 \%$, respectively. These rates are much lower than that of the DRC. Hence, malnutrition remains a significant health burden in the DRC.

This study also found a relationship between malnutrition, maternal healthcare coverage and the geographic distribution of provinces in the DRC. Central provinces in the DRC generally had a higher prevalence of malnutrition among children as well as lower coverage of maternal healthcare. This can be attributed to relatively unprosperous economies in these provinces (Fig. 1). Although these provinces have agricultural potential, due to the vast deposits of diamonds, people tend to rely on the artisanal mining industry for a living, instead of involving in agriculture ${ }^{(36)}$. The deterioration of the transportation network also poses negative impacts on food security ${ }^{(37)}$. Provinces in this region are landlocked with irregular train service in bad condition, which is difficult to reach. Furthermore, the violence that erupted in Kasaï during the August 2016 hindered the transportation of essential supplies, which negatively impacted the economy, causing price hikes on items such as food. As a consequence, hundreds of thousands of malnourished children were at increased risk of starvation ${ }^{(36)}$.

Over the years, the DRC's Katanga region has been faced with chronic instability. However, children's nutrition status and the coverage of maternal healthcare are relatively better in comparison to central provinces, which could be attributed to several factors. Firstly, the Katanga region is one of the three main economic hubs in the DRC with large commercial and industrial bases, highly developed mining industries, and agricultural sectors ${ }^{(38)}$. Secondly, vast investments and international health assistance have been concentrated in this region. For example, as of 2018, Doctors Without Borders run comprehensive medical programmes including maternal and paediatric health care in these provinces ${ }^{(39)}$. As a result, people residing in these regions are more likely to have access to healthcare resources as well as the motivation to utilise these services. 
Our study further confirms the relationship between malnutrition and socio-economic inequalities. Results of the descriptive analysis show that as households' wealth index scores increased, the prevalence of malnutrition decreases, while the coverage rate for maternal healthcare services increases. As Muennig and Su pointed out, money plays an important role in the health of individuals, especially in very poor countries where food is a critical element of survival and requires financial capabilities ${ }^{(40)}$. The random intercept linear regression model in our study (Table 2) confirms that the household's wealth significantly improves the nutrition status of the children. The relationship between poverty and malnutrition has also been elaborated by Müller and Krawinkel, such that poverty leads to insufficient household food security, insufficient child and maternal care, and unhealthy environments ${ }^{(41)}$, which in turn cause malnutrition.

Historically, many studies in developing countries (such as Ethiopia, Indonesia and Bangladesh) have proved that community factors, such as domestic sanitation and healthcare service, are closely related to variations in children's nutritional status ${ }^{(42-44)}$. Insufficient health services and an unhealthy environment are also important contextual factors that may contribute to worsening rates of malnutrition in the UNICEF framework of causes of malnutrition (UNICEF 1990) ${ }^{(45)}$. As demonstrated by the UNICEF framework, malnutrition is determined by a range of factors relying on the implementation of interventions by a multitude of sectors. Previous researches showed a strong relationship between the nutritional status of children and its immediate and underlying determinants. For example, in Gabon, feeding practices and access to improved water and sanitation were the best predictors of stunting ${ }^{(46)}$. In both Bangladesh and Vietnam, household food security, better caregiver nutrition knowledge and hygiene practices were positively associated with stunting ${ }^{(47)}$. However, results in Congo show that underlying causes such as domestic sanitation and maternal healthcare have little impact on children's malnutrition while taking basic causes, namely economic structure into account. Using the principal component factor method, we identify the maternal healthcare index as a proxy for healthcare accessibility among households. To our surprise, the maternal healthcare index had no statistically significant association with children's nutrition status after including household wealth score and mother's education level. One potential explanation for this finding is that the child nutrition programme may have not been well integrated with maternal healthcare programmes in the DRC, as a result of a fragmented health system that is observed across and within disease control programmes. According to the country report from WHO, between 2006 and 2012, altogether 195 projects and programmes in the health sector of the DRC had external funding but lacked functional coordination among the different health programmes, even when housed in the same building ${ }^{(48)}$. In conclusion, even though maternal healthcare is accessible to households, it may not ensure the availability of child healthcare. Another possible explanation on why the maternal healthcare index has no impact on children's nutrition status may be attributed to quality issues present in the healthcare delivery system. Since the 1990s, governmental funding for the public health sector has declined in the DRC, and health financing is highly accounted for by out-of-pocket payments $(39 \%$ in $\left.2016^{(8)}\right)$ and external aid ( $42.5 \%$ in $2017^{(8)}$ ). With little public funding and weak national leadership, health sector regulation in the DRC has digressed. Additionally, in 2017, the infant mortality in the DRC was 43 per 1000 live births, the child mortality was 70 per 1000 births $^{(49)}$ and the maternal mortality ratio was estimated at 693 per 100000 live births in $2015^{(50)}$. Although healthcare accessibility exists, poor-quality healthcare at delivery may prohibit children from fully benefiting from these services.

To further assess the factors associated with children's nutrition status among vulnerable populations, we extracted $20 \%$ of the poorest households and $20 \%$ of the richest households from the overall population. We followed this by employing a multivariate regression where we found that residing in urban areas and children whose mothers had secondary schooling and higher were protective factors for children among the poorest households after controlling for wealth score. Also, urbanisation has both a direct and an inverse association with child mortality among sub-Saharan African countries, and the DRC, in particular, has experienced the highest reduction in child mortality as a result of urbanisation ${ }^{(51)}$. This finding is consistent with the reduction in child malnutrition in our study. The benefits of residing in urban areas include the availability of various food products, better infrastructure and more accessible healthcare resources due to the concentration of health workers ${ }^{(48)}$. Besides, the mother's education has shown to be an independent protective factor for the nutrition status of the children living in the poorest households. Moreover, previous literature emphasised the importance of a mother's education on children's health and nutrition ${ }^{(52,53)}$. The various pathways through which a mother's education promotes a child's nutrition status include the acquisition of health knowledge, adherence to recommended feeding practices for children and increased command over resources.

There are some limitations to this study. Firstly, although we found significant associations between child malnutrition with geographical and socio-economic inequalities in this study, causal inference cannot be drawn as this was a cross-sectional study. Secondly, healthcare access is surrogated by maternal healthcare coverage in this study. This was due to the lack of available data to measure a household's access to healthcare, such as distance to the closest clinic and affordability of medical visits. The study also assumed a linear additive relationship between the 
explanatory and dependent variables. The possibility of a non-linear relationship was not explored in our study. Finally, the household's wealth status was measured based on asset endowments only.

\section{Conclusion}

This study revealed considerable socio-economic inequalities in nutritional status among children in the DRC and the prevalence of malnutrition is higher in underdeveloped regions.

It calls for an urgent need for nutrition promotion in integrated services of maternal and child healthcare. Policy implementation of better healthcare should particularly prioritise central provinces and improve nutrition education for less-educated mothers.

\section{Acknowledgements}

Acknowledgements: None. Financial support: This work was supported by the National Natural Science Foundation of China (grant number 72074130) and the Spring Breeze Foundation of Tsinghua University (grant number 20203080035). Kun Tang received these two grants. Conflict of interest: There are no conflicts of interest. Authorship: K.T., X.Q. and Y.F. contributed to the study concept and design, results interpretation, drafting, and revision of the manuscript and approved the final version of the manuscript. X.Q., Y.F. and Q.H. did the statistical analysis. X.Q. and Y.W. contributed to the introduction drafting and results interpretation. W.C. contributed to the statistical analysis and results interpretation. X.Q., Q.H., J.H. and R.T. contributed to the revision of the manuscript. K.T. is the guarantor of this work and, as such, had full access to all the data used in the study and takes responsibility for the integrity of the data and the accuracy of the data analysis. X.Q. and Y.F. contributed to the study equally, listed as co-first authors. Ethics of human subject participation: This study was conducted according to the guidelines laid down in the Declaration of Helsinki, and all procedures involving research study participants were approved by the Ministry of Plan of the DRC. Written informed consent was obtained from all subjects/patients. The data used in the study consisted of a publicly available de-identified dataset, which was retrieved from the UNICEF MICS website with permission.

\section{Supplementary material}

For supplementary material accompanying this paper visit https://doi.org/10.1017/S1368980021004249

\section{References}

1. The World Bank \& World Development Indicators (2019) Population, Total - Congo, Dem. Rep. https://data.world bank.org/indicator/SP.POP.TOTL?locations=CD (accessed June 2020).

2. The World Bank (2016) GDP growth (annual \%) - Congo, Dem. Rep. https://data.worldbank.org/indicator/NY.GDP. MKTP.KD.ZG?locations=CD (accessed April 2021).

3. Kuwonu F (2016) DRC Economy: The Giant Awakens. https://www.un.org/africarenewal/magazine/august-2016/ drc-economy-giant-awakens (accessed April 2021).

4. The World Bank (2021) The World Bank in DRC. https:// www.worldbank.org/en/country/drc/overview (accessed April 2021).

5. The World Bank (2019) World Bank Maternal Mortality Ratio (Modeled Estimate, Per 100,000 Live Births) - Congo, Dem. Rep. https://data.worldbank.org/indicator/SH.STA.MMRT? locations $=$ CD (accessed April 2021).

6. OCHA Services (2003) Mortality, Violence and Lack of Access to Healthcare in the Democratic Republic of Congo. https:// reliefweb.int/report/democratic-republic-congo/mortalityviolence-and-lack-access-healthcare-democratic-republic (accessed April 2021).

7. Hailegebriel $\mathrm{T}$ (2018) Undernutrition, intestinal parasitic infection and associated risk factors among selected primary school children in Bahir Dar, Ethiopia. BMC Infect Dis 18, 394.

8. Asia Catalyst (2007) AIDS Blood Scandals: What China Can Learn from the World's Mistakes. New York: Asia Catalyst.

9. Watkins K (2016) The State of the World's Children 2016: A Fair Chance for Every Child. New York, NY: UNICEF.

10. Victora CG, Adair L, Fall C et al. (2008) Maternal and child undernutrition: consequences for adult health and human capital. Lancet 371, 340-357.

11. Black RE, Victora CG, Walker SP et al. (2013) Maternal and child undernutrition and overweight in low-income and middle-income countries. Lancet 382, 427-451.

12. Roth TL \& David Sweatt J (2011) Annual research review: epigenetic mechanisms and environmental shaping of the brain during sensitive periods of development. J Child Psychol Psychiatry 52, 398-408.

13. Prentice AM, Ward KA, Goldberg GR et al. (2013) Critical windows for nutritional interventions against stunting. $\mathrm{Am}$ J Clin Nutr 97, 911-918.

14. Grantham-McGregor S (1995) A review of studies of the effect of severe malnutrition on mental development. J Nutr 125, 2233S-2238S.

15. Grantham-McGregor S, Cheung YB, Cueto S et al. (2007) Developmental potential in the first 5 years for children in developing countries. Lancet 369, 60-70.

16. Bleakley H (2010) Health, human capital, and development. Annu Rev Econ 2, 283-310.

17. Luo J, Qu Z, Rockett I et al. (2010) Employment status and self-rated health in north-western China. Public Health 124, 174-179

18. Link BG \& Phelan J (1995) Social conditions as fundamental causes of disease. J Health Soc Behav 35, 80-94.

19. Kanjilal B, Mazumdar PG, Mukherjee M et al. (2010) Nutritional status of children in India: household socio-economic condition as the contextual determinant. Int J Equity Health 9, 19.

20. Ruel MT \& Alderman H (2013) Nutrition-sensitive interventions and programmes: how can they help to accelerate progress in improving maternal and child nutrition? Lancet 382, 536-551.

21. Chirwa TF, Mantempa JN, Kinziunga FL et al. (2014) An exploratory spatial analysis of geographical inequalities of 
birth intervals among young women in the Democratic Republic of the Congo (DRC): a cross-sectional study. BMC Pregnancy Childbirth 14, 271.

22. Kennedy G, Nantel G, Brouwer ID et al. (2006) Does living in an urban environment confer advantages for childhood nutritional status? Analysis of disparities in nutritional status by wealth and residence in Angola, Central African Republic and Senegal. Public Health Nutr 9, 187-193.

23. Heaton TB, Crookston B, Pierce H et al. (2016) Social inequality and children's health in Africa: a cross sectional study. Int J Equity Health 15, 92.

24. Emina JB-O, Kandala N-B, Inungu J et al. (2011) Maternal education and child nutritional status in the Democratic Republic of Congo. J Public Health Epidemiol 3, 576-592.

25. Kandala N-B, Madungu TP, Emina JB et al. (2011) Malnutrition among children under the age of five in the Democratic Republic of the Congo (DRC): does geographic location matter? BMC Public Health 11, 261.

26. Kaur S (2007) Economic freedom, inequality and poverty: re-examining the role of government. Indian Econ J 55, 96-118.

27. McAuley A, Denny C, Taulbut M et al. (2016) Informing investment to reduce inequalities: a modelling approach. PLoS One 11, e0159256.

28. Stewart E \& Smith KE (2015) 'Black magic'and'gold dust': the epistemic and political uses of evidence tools in public health policy making. Evid Policy 11, 415-437.

29. Rosenzweig MR \& Wolpin KI (1991) Inequality at birth: the scope for policy intervention. J Econom 50, 205-228.

30. WHO (2006) WHO Child Growth Standards: Length/Heightfor-Age, Weight-for-Age, Weight-for-Length, Weight-forHeight and Body Mass Index-for-Age: Methods and Development. https://www.who.int/publications/i/item/ 924154693X (accessed August 2021).

31. UNICEF (2021) MICS6 Tools. https://mics.unicef.org/ tools\#survey-design (accessed June 2021).

32. Novignon J, Aboagye E, Agyemang OS et al. (2015) Socioeconomic-related inequalities in child malnutrition: evidence from the Ghana multiple indicator cluster survey. Health Econ Rev 5, 1-11.

33. Di Cesare M, Bhatti Z, Soofi SB et al. (2015) Geographical and socioeconomic inequalities in women and children's nutritional status in Pakistan in 2011: an analysis of data from a nationally representative survey. Lancet Glob Health $\mathbf{3}$, e229-e239.

34. Erwin K (2006) The circulatory system: blood procurement, AIDS, and the social body in China. Med Anthropol $Q$ 20, 139-159.

35. Emerson E, Savage A, Llewellyn G et al. (2020) Prevalence of underweight, wasting and stunting among young children with a significant cognitive delay in 47 low-income and middle-income countries. I Intellect Disabil Res 64, 93-102.
36. Rodriguez-Alvarez E, Lanborena N, Borrell LN et al. (2018) Obesity inequalities according to place of birth: the role of education. Int J Environ Res Public Health 15, 1620.

37. Weijs B, Hilhorst D, Ferf A et al. (2012) Livelihoods, Basic Services and Social Protection in Democratic Republic of the Congo. Wageningen: Wageningen University.

38. International Trade Administration (2017) Congo, Democratic Republic - Market Overview. https://www.export.gov/article? series $=a 0$ pt0000000GnEdAAK\&type=Country_Commercial_ kav (accessed May 2020).

39. Fox K, Himawan L, France C et al. (2018) The blood donation ambivalence survey: measuring conflicting attitudes about giving blood. Transfus Med 28, 193-199.

40. Muennig P \& Su C (2013) Introducing Global Health: Practice, Policy, and Solutions. John Wiley \& Sons.

41. Müller O \& Krawinkel M (2005) Malnutrition and health in developing countries. CMAJ 173, 279-286.

42. Wirth JP, Rohner F, Petry N et al. (2017) Assessment of the WHO stunting framework using Ethiopia as a case study. Matern Child Nutr 13, e12310.

43. Beal T, Tumilowicz A, Sutrisna A et al. (2018) A review of child stunting determinants in Indonesia. Matern Child Nutr 14, e12617.

44. Islam MS, Zafar Ullah AN, Mainali S et al. (2020) Determinants of stunting during the first $1000 \mathrm{~d}$ of life in Bangladesh: a review. Food Sci Nutr 8, 4685-4695.

45. UNICEF (1990) Strategy for Improved Nutrition of Children and Women in Developing Countries. New York: UNICEF.

46. Blaney S, Beaudry M, Latham M et al. (2009) Determinants of undernutrition in rural communities of a protected area in Gabon. Public Health Nutr 12, 1711-1725.

47. Nguyen PH, Headey D, Frongillo EA et al. (2017) Changes in underlying determinants explain rapid increases in child linear growth in Alive \& Thrive study areas between 2010 and 2014 in Bangladesh and Vietnam. J Nutr 147, 462-469.

48. World Health Organization (2015) Improving Health System Efficiency: Democratic Republic of the Congo: Improving Aid Coordination in the Health Sector. Geneva: World Health Organization.

49. Gill T, Jones K, Hammett T et al. (2016) Agricultural education and training system capacity development for sub-Saharan Africa: the role of InnovATE. J Dev Commun Stud 4, 401-415.

50. Li L, Liu P, Sun H et al. (2017) Male or female, who is happier? Stat Res 34, 82-93.

51. Anyamele OD (2009) Urban and rural differences across countries in child mortality in sub-Saharan Africa. $J$ Health Care Poor Underserved 20, 90-98.

52. Makoka D (2013) The Impact of Maternal Education on Child Nutrition: Evidence from Malawi, Tanzania, and Zimbabwe. Calverton, Maryland, USA: ICF International.

53. Fadare O, Amare M, Mavrotas G et al. (2019) Mother's nutrition-related knowledge and child nutrition outcomes: empirical evidence from Nigeria. PLoS One 14, e0215110. 